\title{
Behavioral and Physiological Effects of Examiner Sex on Process and Reactive Schizophrenics
}

Rita Kluczny McDonald

Loyola University Chicago

Follow this and additional works at: https://ecommons.luc.edu/luc_diss

Part of the Psychology Commons

\section{Recommended Citation}

McDonald, Rita Kluczny, "Behavioral and Physiological Effects of Examiner Sex on Process and Reactive Schizophrenics" (1971). Dissertations. 1205.

https://ecommons.luc.edu/luc_diss/1205

This Dissertation is brought to you for free and open access by the Theses and Dissertations at Loyola eCommons. It has been accepted for inclusion in Dissertations by an authorized administrator of Loyola eCommons. For more information, please contact ecommons@luc.edu. (c) (i) $(9)$

This work is licensed under a Creative Commons Attribution-Noncommercial-No Derivative Works 3.0 License. Copyright @ 1971 Rita Kluczny McDonald 
BEHAVIORAL AND PHYSIOLOGICAL EFFECTS OF EXAMINER SEX ON PROCESS AND REACTIVE SCHIZOPHRENICS

Rita Kluczny McDonald

A Dissertation Submitted to the Faculty of the Graduate School of Loyola University in Partial Fulfillment of the Requirements for the Degree of Doctor of Philosophy

February

1971 
ABSTRACT

This investigation studied the effect of examiner sex on the word associations of 40 schizophrenics and concurrently assessed physiological indices of emotional arousal under stressful conditions. The hypothesis that word associations would show less disturbance when the $\underline{E}$ and $\underline{S}$ were of the same sex was not supported. On the contrary, for the recall of associations measure, three out of four groups performed more poorly when $\underline{E}$ and $\underline{S}$ were the same sex. However, results using a heart rate varlability measure supported the general hypothes is of less stress reaction when the $\underline{E}$ and $\underline{S}$ were the same sex. Heart rate variability was significantly greater with heterosexual E-S pairings than with same-sex E-S pairs.

The second hypothesis, that examiner sex differences would have more effect on reactive than on process schizophrenics was partially supported by the findings in the initial breathing rate. For this measure, both male and female reactives showed higher initial respiration rates with male Es than with female Es, while the process groups showed no systematic effect of $\underline{E}$ sex.

Generally, effects of $\underline{E}$ sex and the process-reactive classification were found in both behavioral and physiological measures, but a measure of institutionalization was not related to any other measure. The presence of a female $\underline{E}$ was accompanied by lower initial respiration rates in male and female reactive groups. Also, when $\underline{E}$ and $\underline{S}$ were of different sexes, heart rate variability was greater. Finally, in all 
groups except the process males, the associational processes were more stable with heterosexual E-S pairs.

Process-reactive differences were found in heart rate and stability of associations. The combined male and female process Ss showed a higher initial and average heart rate. The combined reactives showed more stable associational processes.

When behavioral, physiological, and demographic measures were intercorrelated for the entire group, relationships between behavioral and physiological measures were found which appeared to be independent of institutionalization and the process-reactive distinction. In general, lower levels of pathology were accompanied by less reaction to the stressful situation, as well as by less variability in breathing throughout the examination and less tendency to block (i.e., shorter reaction times). 


\section{LIFE}

Rita Kluczny McDonald was born in Milwaukee, Wisconsin, September 3, 1929. She was graduated from St. Mary's Academy in Milwaukee, June, 1947. She began her undergraduate studies at Alverno College, Milwaukee, in Jume, 1957, and graduated magna cum laude in May, 1962 with the degree of Bachelor of Arts.

She began her graduate studies at Marquette University in September, 1965 and received the degree of Master of Science in August, 1969.

She taught at the junior high school level from 1950 through 1965. From November, 1967, to November, 1969, she held a V.A. traineeship. From April, 1970 to the present time she has been. Chief Psychologist at Kiwanis Children's Center of the Curative Workshop of Milwaukee and Lecturer in the Department of Psychology at Marquette University, Milwaukee. 


\section{ACKNOWLEDGMENTS}

The author wishes to express her gratitude to Drs. Ronald Walker, William A. Hunt, and Jeanne Foley, who served as members of her advisory committee and offered helpful comments and suggestions. Special thanks are due Dr. Alan S. De Wolfe, without whose enthusiastic support, consistent availability, and genuine interest this research would not have been implemented. The author is likewise indebted to Dr. Albert Erlebacher for his consultation on statistical analyses and to Mr. Joseph Konieczny, whose competence and accuracy in recording physiological data were invaluable. The cooperation of the student examiners in this study is greatly appreciated, as are the time and resources made available to the author by the Veterans Administration Hospital, Downey, Illinois. 


\section{TABLE OF CONTENTS}

Chapter 1 - Introduction 1

Chapter 2 - Method 7

Chapter 3 - Results 12

$\begin{array}{ll}\text { Chapter } 4 \text { - Discussion } & 47\end{array}$

Chapter 5 - Summary $\quad 51$

References 53 
Clinical psychologists have long been concerned with the effects of the examiner on the outcome of psychological testing. Lord (1950) and Schafer (1954) were among the first to recognize the influence of the $E$ variable, particularly in Rorschach performance. A historical review by Kintz, Delprato, Mettee, Persons, and Schappe (1965) revealed that although the influence of the $\underline{E}$ has been generally acknowledged, an unconcerned attitude towards this phenomenon had been taken, especially by experimental psychologists. Recent investigations, however, have shown somewhat striking results which indicate that Es may and do influence their data. Rosenthal (1963, $1964 a, 1964 b, 1966)$ has presented ample evidence to substantiate the contention that E's attributes, biases, and outcomeorientation induce significant variability in S's performance in psychological testing situations. Specific personality characteristics of the psychologist (i.e., warmth, trust, likeability) were shown to be important determinants of test behavior. Brenner (1967) explored the effect of the E's orientation (warm and accepting vs. cold and aloof) on the course of free association. It was found that $\mathrm{Ss}$ in the rebuff condition gave significantly more common associations after their relationship with the investigator. Walker and Firetto (1965) and Walker, Davis, and Firetto (1968) attempted to assess the effect of the clergyman/layman role. While analysis of this variable yielded no significant difference, "true-role" and "simulated-role" analyses indicated some sig- 
nificant sex differences in performance. Winkel and Sarason (1964), in a study of subject, experimenter, and situational variables, found that female Ss performed best when tested by low-anxious Es.

Effects of Examiner

The effect of E's sex on normal Ss was investigated by Stevenson and Allen (1964). Significant differences in base rate and in performance after the base rate period in a simple sorting task were found to be a function of the sex of $\underline{E}$ and of the interaction between the sex of $\underline{E}$ and the sex of $\underline{S}$. There was a higher rate of performance with male experimenters and female subjects and with female experimenters and male subjects than when the experimenter and subject were of the same sex. Similar results were obtained by Stevenson and Knights (1962) with mentally retarded subjects with an average IQ of less than 60. Glixman (1967) studied the effects of the E's and S's sex upon categorizing behavior and found that female and male Es elicited a significantly different distribution of items over categories. The interaction of the sex of subject and the sex of experimenter in a serial learning situation was investigated by Littig and Wadde11 (1967), who made a special effort to reduce the effects of individual differences among Es. A nested $2 \times 2 \times 3$ design was used: one dimension representing the sex of $\underline{S}$; one the sex of $\underline{E}$; and one the reward, neutral and pun- 
ishment reinforcement conditions. Results showed that the sex of $\underline{S}$ and the reinforcement condition affected the rate of learning. There was an interaction between the sex of $\underline{S}$ and

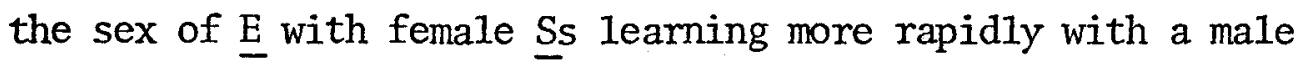
E. Fox (1968) focused on the experimenter variable in dream research. After an accomodation night, sleep was monitored and dream narratives were elicited. These showed a greater incidence of crowds and groups of people in the dreams when there was a heterosexual E-S relationship. Hostility was lower when a male $\underline{S}$ was with a male $\underline{E}$ and dependency was lower when a female $\underline{S}$ was with a male $\underline{E}$. References to the experimental situation in the dream content remained unchanged over the six nights during which the study was in progress. Datta and Drake (1968), in examining the figure drawings of disadvantaged preschool children for observable sexual differentiation, found no significant boy-girl differences in the proportion of same-sex figures obtained by male examiners. However, a larger proportion of girls tested by females drew same-sex figures.

There is a dearth of empirical evidence related to the effect of $\underline{E}$ 's sex on schizophrenic Ss. Lefcourt, Rotenberg, Buckspan, and Steffy (1967) hypothesized a difference in visual interaction between process and reactive male schizophrenics, and proposed that this difference was a function of 
the examiner's sex. Their findings showed that differences in length of eye contact were not significant, but frequency was. Process patients looked less often at females than at males and differed from reactives mostly when interacting with females.

The Process-Reactive Distinction

With respect to the process-reactive dimension in schizophrenia, the evidence on levels of activation using physiological measures is not clearly consistent, particularly for the process Ss' low level of activation. DeVault (1957) found process and normal groups equal in resting GSR and heart rate with the reactive group significantly higher than both $(R>P=N)$. However, Reynolds (1963), with chronic process and reactive groups, found reactives consistently lower in blood pressure, heart rate, and breathing measures. Bernstein (1967) has suggested that vigilance for generalized environmental demands remains high in chronic schizophrenia, but specific information input is reduced. The data from behavioral measures of performance in a variety of tasks, however, have quite consistently found the process schizophrenics to show signs of responding with minimal energy in their performance and reactives to respond with a great deal of energy (e.g., Crider, Grinspoon, and Maher, 1965; Reisman, 1960;

Reynolds, 1965; Smith, 1961; Zlotowski and Baken, 1963).

The data on autonomic and behavioral reaction to ex- 
ternal stimulation is far less equivocal than is the data on the level of activation. There are studies in which no differences were found, but almost invariably when the groups differed, the reactives had greater reaction than the process Ss. Studies with physiological measures. (Crider, Grinspoon, and Maher, 1965; DeVault, 1957; Ward and Carlson, 1966; and Struve, 1966) al1 indicated $\mathrm{R}>\mathrm{P}$ in response and the latter three studies found $R \rightarrow N>P$. A number of investigations using behavioral measures of response to external stimulation (e.g., DeWolfe, 1962; True, 1966; Smith, 1961; Moriarity and Kates, 1962; and Berman, 1963) found the reactives to be more responsive.

Studies comparing process and reactive groups on word association performance have produced conflicting results. Dokecki, Polidoro, and CromweII (1965) found significant differences between process and reactive groups in commonality and stability of word associations with the process Ss scoring significantly lower on both measures. On the other hand, Fuller and Kates (1969) found no significant differences between normals and process and reactive schizophrenics in commonality or idiosyncracy of word association repertoires. Humphries (1961) found no significant differences between process and reactive subgroups in stability of associations and Ries and Johnson (1967) found significant differences in commonality only in a subsample of process and reactive $\underline{S}$ who had been hospitalized for at least five years. The latter study showed that in reactive patients, but not in process 
patients, word-association commonality improves with length of hospitalization. In process patients, commonality tends to be reduced over time.

The purpose of the present study was to evaluate the effect of the examiner's sex on the word associations and concomitant state of physiological arousal of schizophrenic subjects. Specifically, the following hypotheses were tested:

1) Word associations of schizophrenic subjects show fewer disturbances when the sex of the examiner is the same as that of the subject, and

2) The sex difference of examiners has a greater physiological effect on reactive schizophrenics than on those classified as process schizophrenics, since the former are generally more responsive to external stimuli than the latter. 
Method

Subjects

Forty subjects were tested by ten examiners. Each of the experimenters tested four patients, one from each of the following groups:

1) male process schizophrenics

2) male reactive schizophrenics

3) female process schizophrenics

4) female reactive schizophrenics.

The subjects were classified as schizophrenics on the basis of the diagnosis made upon admission to the hospital, the hospital record diagnosis, and the agreement of the staff psychologist in the respective ward. They were sub-classed as process or reactive on the basis of the General Information Questionnaire (DeWolfe, 1968), a social history questionnaire which elicits information to be rated on the Phillips scale (Philips, 1953) and is scored objectively to determine the prepsychotic level of social adjustment.

The four groups of subjects were matched on age and education in order to limit, as far as possible, the effects of these variables on word associations. Within each of the four groups, half the number of subjects were tested by a male examiner and half by a female examiner. This selection was random and yielded eight groups of subjects. 
Examiners

The five male and five female examiners were college students enrolled in an upper division psychology course, inexperienced in dealing with psychotic subjects, and ranging in age from 19 to 22 . They were trained in the following procedures :

1) introducing themselves to patients,

2) explaining the nature and purpose of the various physiological measuring instruments,

3) attaching these instruments to the patients,

4) administering the word association test, recording reaction time and responses, and tapping a foot pedal to record each stimulus word, and

5) detaching the instruments and thanking the patient for his cooperation.

The training period for each examiner consisted of two demonstrations and at least two practice sessions, all in the presence of the investigator and a technician, who ensured that the instruments were attached properly for recording purposes. When the investigator and the technician had ascertained that an examiner was thoroughly familiar with the foregoing procedures, that examiner was permitted to test four patients, one from each of the diagnostic categories. He was instructed, moreover, to label each of his records with his own name, the name of the patient, and the date of testing. 
The record was forwarded immediately to the investigator, who attached it to the corresponding polygraph record. Measures

The following instruments were used: The General Information Questionnaire, a social history questionnaire designed to classify the schizophrenic patient as process or reactive; the Word Association test developed by Moran, Mefford, and Kimble (1964); and certain physiological measures of level of activation, i.e., respiration, pulse, galvanic skin response, and bodily movement.

A11 Ss were given the same list of 50 words in the word association task. The list is one of seven altemate forms produced from the 400 words used by Moran et al (1964).

The word associations were scored for relatedness on a five-point scale developed by Moran (1953). Two other indicators of pathology, the per cent of words not recalled and reaction time, measured in tenths of seconds, were also used. An initial record of the physiological data, taken at the beginning of the examination, was examined. This included the initial log of skin conductance times 100, the initial rate of bodily movement per minute, the initial breathing rate in cycles per minute, and the initial heart rate in beats per minute. These initial values were the mean of the readings for the first two minutes.

Polygraph readings were also taken at one-minute intervals in each record, and a mean of all readings was found for 
each of the four physiological measures. A record of the minute-to-minute variability, i.e., the mean of the absolute differences between the scores for each successive minute, was also analyzed. Procedure

Upon arrival at the testing center, the patient was met by the examiner, who introduced himself and explained that the patient was participating in a hospital research project which involved a word task and certain physiological measures. He then proceeded to familiarize the patient with the nature and purpose of the various measuring instruments. The subject was invited to sit in a chair and the instruments were attached. Thereupon, the word association test was administered, using the speed-set and verbal stimulus and verbal response condition. The following instructions were given:

"I am going to say a word. As soon as you hear the word, say the first word that comes to your mind. Remember, the very first word that comes to mind. Is that clear?" The subject's reaction time and responses were recorded after each stimulus word. After the complete list of 50 words was administered, the examiner directed the patient as follows: 'Now I am going to go over the list of words again. This time I would like you to give me the same word you gave the first time. Do you understand?"

Again, the reaction time and responses were recorded after each stimulus presentation. 
If the patient's response, under either set of directions, was delayed beyond 15 seconds, he was reminded to say the first word that came to his mind after the stimulus word. If he offered more than one word, he was asked to remember the instructions, which specified a single-word response. When the word association test was completed, the instruments were detached and the patient was thanked for his cooperation and dismissed. 


\section{Results}

A $2 \times 2 \times 2$ analysis of Latin squares was applied to the following data:
a) reaction time
b) relatedness of word associations
c) per cent of words not recalled
d) initial value of each of four physiological measures
e) mean of minute-to-minute readings of four physio- logical measures
f) minute-to-minute variability of four physiological measures.

Among the three measures of pathology in word associations ( $a, b$ and $c$ above), there were no significant findings in the reaction-time data and the relatedness of word associations, but a main effect was found on the process-reaction dimension in the per cent of words not recalled. The process schizophrenics recalled significantly fewer associations than did the reactives $(\underline{p}<.025)$. On the same measure, a significant triple interaction (process-reactive $\mathrm{x}$ patient's sex $x$ examiner's sex) was seen $(\underline{p}<.01)$. Reactive and process females performed more poorly in the presence of a female examiner, and reactive males recalled fewer words in the presence of a male examiner. Thus, the performance of females, 
both process and reactive, and reactive males was poorer in the presence of a same-sex examiner than in the presence of an opposite-sex examiner. Process males showed no reaction to the sex of the examiner. These data are presented in Tables $1-6$. The first hypothesis of the present study, i.e., that word associations of schizophrenic subjects show fewer disturbances when the sex of the examiner is the same as that of the subject, was not supported by these findings. Rather, the significant results of this study were in opposition to the first hypothesis.

The analysis of the physiological data yielded a significant triple interaction in initial breathing rates $(p<.05)$. The sex of the examiner had a differential effect on both male and female reactives, but not on the process patients. This finding offered partial support for the second hypothesis of the present study, i.e., that the sex difference of examiners has a greater physiological effect on reactives than on process schizophrenics. The initial respiration rate was lower for all reactive patients when the examiner was a female. This effect did not extend over the entire testing session, nor was there any significant variability across the testing period. These data are presented in Tables $7-12$.

Perhaps the most noteworthy among the physiological findings of the present study is that involving heart rate. In both the initial measure and the average across the entire testing session (average of all the readings), there was 
TABLE 1

Means and Standard Deviations

for Reaction Time

in Tenths of Seconds

Subclass

$\underline{S} \operatorname{Sex}$

E Sex

Mean

S.D.

Process

Male

Male

3.60

2.33

Process

Male

Female

3.14

1.78

Process

Female

Female

3.54

0.45

Process

Female

Male

3.10

0.83

Reactive

Male

Male

3.86

0.56

Reactive

Male

Female

3.60

1.12

Reactive

Female

Female

4.28

1.27

Reactive

Female

Male

3.32

1.10 
TABLE 2

\author{
Analysis of Variance \\ of Reaction Time \\ in Tenths of Seconds
}

Source

df

MS

F

$\mathrm{p}$

E sex

1

0.27

$<1.00$

NS

E/E sex

8

2.86

PR

1

1.90

1.19

NS

PR x E sex

1

0.33

$<1.00$

NS

$P R \times E / E$ sex

8

1.60

$S$ sex

1

0.01

$<1.00$

NS

$S \operatorname{sex} x E \operatorname{sex}$

1

2.66

2.53

NS

$S \operatorname{sex} x E / E \operatorname{sex}$

8

1.05

PR x S sex

1

0.34

$<1.00$

NS

$P R \times S \operatorname{sex} \times E \operatorname{sex}$

1

0.04

$<1.00$

NS

$\mathrm{PR} \times \mathrm{S} \operatorname{sex} \times \mathrm{E} / \mathrm{E} \operatorname{sex}$

8

3.20

Tota1 
TABLE 3

Means and Standard Deviations

for Relatedness of Associations

$\begin{array}{lllll}\text { Subclass } & \text { S Sex } & \text { E Sex } & \text { Mean } & \text { S.D. } \\ \text { Process } & \text { Male } & \text { Male } & 2.78 & 0.26 \\ \text { Process } & \text { Male } & \text { Female } & 2.96 & 0.19 \\ \text { Process } & \text { Female } & \text { Female } & 3.06 & 0.20 \\ \text { Process } & \text { Female } & \text { Male } & 2.90 & 0.23 \\ \text { Reactive } & \text { Male } & \text { Male } & 2.86 & 0.40 \\ \text { Reactive } & \text { Male } & \text { Female } & 3.06 & 0.19 \\ \text { Reactive } & \text { Female } & \text { Female } & 3.12 & 0.17 \\ \text { Reactive } & \text { Female } & \text { Male } & 2.88 & 0.34\end{array}$


TABLE 4

Analysis of Variance

of Relatedness of Association

Source

E sex

E/E sex

PR

PR $\times$ E sex

$\mathrm{PR} \times \mathrm{E} / \mathrm{E}$ sex

$S \operatorname{sex}$

$S \operatorname{sex} x \mathrm{E} \operatorname{sex}$

$S \operatorname{sex} x E / E \operatorname{sex}$

PR $x$ S sex

$P R \times S \operatorname{sex} \times E \operatorname{sex}$

$P R \times S \operatorname{sex} \times E / E \operatorname{sex}$ df

1

8

1

1

8

1

1

8

1

1

8

Total
MS

0.400

0.127

0.036

1.224

$<1.000$

0.004

0.029

0.064

4.238

NS

0.000

$<1.000$

0.015

0.000

$<1.000$

NS

0.024

$<1.000$

0.175

$\mathrm{p}$

NS

NS

NS

NS

8.175




\author{
TABLE 5 \\ Means and Standard Deviations \\ for Per Cent of Words not Recalled
}

$\begin{array}{llllr}\text { Subclass } & \text { S Sex } & \text { E Sex } & \text { Mean } & \text { S.D. } \\ \text { Process } & \text { Male } & \text { Male } & 26.0 & 11.24 \\ \text { Process } & \text { Male } & \text { Female } & 25.2 & 7.33 \\ \text { Process } & \text { Female } & \text { Female } & 39.8 & 11.63 \\ \text { Process } & \text { Female } & \text { Male } & 22.0 & 15.24 \\ \text { Reactive } & \text { Male } & \text { Male } & 21.4 & 3.87 \\ \text { Reactive } & \text { Male } & \text { Female } & 15.2 & 7.96 \\ \text { Reactive } & \text { Female } & \text { Female } & 26.2 & 13.50 \\ \text { Reactive } & \text { Female } & \text { Male } & 17.8 & 12.94\end{array}$




\section{TABLE 6 \\ Analysis of Variance \\ of Per Cent of Words Not Recalled}

\begin{tabular}{|c|c|c|c|c|}
\hline Source & $d f$ & MS & F & $\mathrm{p}$ \\
\hline E sex & 1 & 235.20 & $<1.00$ & NS \\
\hline $\mathrm{E} / \mathrm{E} \operatorname{sex}$ & 8 & 310.90 & & \\
\hline PR & 1 & 570.02 & 7.66 & $<.025$ \\
\hline$P R \times E$ sex & 1 & 99.23 & 1.31 & NS \\
\hline $\mathrm{PR} \times \mathrm{E} / \mathrm{E} \operatorname{sex}$ & 8 & 74.38 & & \\
\hline$S \operatorname{sex}$ & 1 & 207.03 & 1.32 & NS \\
\hline$S \operatorname{sex} x E \operatorname{sex}$ & 1 & 697.23 & 4.44 & NS \\
\hline$S \operatorname{sex} \times E / E \operatorname{sex}$ & 8 & 156.38 & & \\
\hline $\mathrm{PR} \times \mathrm{S} \operatorname{sex}$ & 1 & 0.70 & $<1.00$ & NS \\
\hline$P R \times S \operatorname{sex} \times E \operatorname{sex}$ & 1 & 568.00 & 11.50 & $<.01$ \\
\hline$P R \times S \operatorname{sex} \times E / E \operatorname{sex}$ & 8 & 49.38 & & \\
\hline
\end{tabular}


TABLE 7

Means and Standard Deviations

for Initial Respiration

in Cycles per Minute

Subclass

$\underline{S} \operatorname{Sex}$

E Sex

Mean

S.D.

Process

Male

Male

22.2

4.67

Process

Male

Female

21.6

2.87

Process

Female

Female

22.2

4.83

Process

Female

Male

22.0

4.73

Reactive

Male

Male

24.6

3.32

Reactive

Male

Female

23.0

5.66

Reactive

Female

Female

19.6

3.92

Reactive

Female

Male

23.0

2.45 


\section{TABLE 8 \\ Analysis of Variance \\ of Initial Respiration \\ in Cycles per Minute}

Source

E sex

$E / E \operatorname{sex}$

PR

PR $x$ E sex

$\mathrm{PR} \times \mathrm{E} / \mathrm{E}$ sex

$S \operatorname{sex}$

$S \operatorname{sex} x E \operatorname{sex}$

$S \operatorname{sex} x E / E \operatorname{sex}$

PR $\times$ S sex

$P R \times S \operatorname{sex} \times E$ sex

Total df

1

8

1

1

8

1

1

8

1

1

25.00

$<1.00$

NS

27.38

3.00

$<1.00$

NS

0.00

$<1.00$

NS

15.88

17.00

$<1.00$

NS

$<1.00 \quad$ NS

37.13

15.00

2.67

NS

6.57

$<.05$

$\mathrm{p}$ S NS
$P R \times S \operatorname{sex} \times E / E \operatorname{sex}$

8

5.63 
TABLE 9

Means and Standard Deviations

for Average Respiration

in Cycles per Minute

Subclass

$\underline{S} \operatorname{Sex}$

$\underline{E} \operatorname{Sex}$

Mean

S.D.

Process

Male

Male

21.8

4.71

Process

Male

Female

20.6

2.33

Process

Female

Female

21.4

4.36

Process

Female

Male

21.0

4.73

Reactive

Male

Male

22.8

2.04

Reactive

Male

Female

21.0

3.35

Reactive

Female

Female

18.6

3.72

Reactive

Female

Male

22.2

2.99 


\author{
TABLE 10 \\ Analysis of Variance \\ of Average Respiration \\ in Cycles per Minute
}

Source

E sex

E/E sex

PR

PR $x$ E sex

$\mathrm{PR} \times \mathrm{E} / \mathrm{E} \operatorname{sex}$

$S \operatorname{sex}$

$S \operatorname{sex} x E \operatorname{sex}$

$S \operatorname{sex} x E / E \operatorname{sex}$

PR x S sex

PR $x \mathrm{~S}$ sex $x \mathrm{E} \operatorname{sex}$

$P R \times S \operatorname{sex} \times E / E$ sex df

1

8

1

1

8

1

1

8

1

1

8

18.00

12.38

1.00

18.00

12.50

1

9.00

1.00

14.63

.

3.00

4.00

$<1.00$

$<1.00$

11.88 
TABLE 11

Means and Standard Deviations

for Respiration Variability

Subclass

$\underline{\mathrm{S}} \operatorname{Sex}$

E Sex

Mean

S.D.

Process

Male

Male

1.90

0.67

Process

Male

Female

2.22

0.89

Process

Female

Female

2.12

0.47

Process

Female

Male

1.98

1.09

Reactive

Male

Male

2.16

1.22

Reactive

Male

Female

1.96

0.95

Reactive

Female

Female

1.50

0.35

Reactive

Female

Male

1.72

0.34 
TABLE 12

Analysis of Variance

of Respiration Variability

Source

$\mathrm{df}$

MS

F

$\mathrm{p}$

E sex

1

0.10

$<1.00$

NS

E/E sex

8

0.35

PR

1

0.50

1.04

NS

PR $x$ E sex

1

0.40

$<1.00$

NS

PR $x$ E/E sex

8

0.48

$S$ sex

1

0.50

$<1.00$

NS

$S \operatorname{sex} x E \operatorname{sex}$

1

0.00

$<1.00$

NS

$S \operatorname{sex} x E / E \operatorname{sex}$

8

1.29

PR $x$ S sex

1

0.50

$<1.00$

NS

$P R \times S \operatorname{sex} x \cdot E \operatorname{sex}$

1

0.50

$<1.00$

NS

$P R \times S \operatorname{sex} \times E / E \operatorname{sex}$

8

1.14

Total 
a significant main effect on the process-reactive dimension. The pulse rate of the process group was significantly higher initially $(\underline{p}<.01)$ and throughout the testing period $(\underline{p}<.001)$. An analysis of heart rate variability yielded a significant interaction between the patient-sex and the examinersex variables, with variability increasing in a heterosexual E-S situation. While the word association findings of the present study did not support the first hypothesis (i.e., that $\underline{S}$ would show greater word association disturbance with opposite sex Es), the increased heart rate variability with the heterosexual $\underline{\mathrm{E}}$ - $\underline{\mathrm{S}}$ conditions indicated greater stress reactivity in this situation. Therefore, at the physiological leve1, the $\underline{S}$ s showed less stress response with Es of the same sex. The data on heart rate are presented in Tables 13 - 18 .

Analyses of initial, average, and variability measures of galvanic skin response and body movement yielded no significant findings for any of the variables in this study (see Tables 19 - 30).

Certain demographic data, i.e., per cent of lifetime spent in psychiatric hospitalization (a measure of chronicity with age taken into account), were also available. These data were compared with the behavioral data (word association scores) and the physiological data by means of the Pearson product-moment correlation coefficient to determine the degree of relationship among the three types of data. Findings 
TABLE 13

Means and Standard Deviations

for Initial Heart Rate

in Beats per Minute

Subclass

$\underline{S} \operatorname{Sex}$

E. Sex

Mean

S.D.

Process

Male

Male

109.4

6.77

Process

Male

Female

97.6

19.21

Process

Female

Female

109.0

20.04

Process

Female

Male

101.0

15.63

Reactive

Male

Male

93.6

10.36

Reactive

Male

Female

82.0

10.14

Reactive

Female

Female

90.6

8.82

Reactive

Female

Male

90.4

18.46 
TABLE 14

$$
\begin{aligned}
& \text { Analysis of Variance } \\
& \text { of Initial Heart Rate } \\
& \text { in Beats per Minute }
\end{aligned}
$$

Source

df

MS

F

$\mathrm{p}$

E sex

1

156.02

$<1.00$

NS

E/E sex

8

170.06

PR

1

2222.00

19.68

$<.01$

PR $x$ E sex

1

3.80

$<1.00$

NS

$P R \times E / E$ sex

8

112.93

$S \operatorname{sex}$

1

40.20

$<1.00$

NS

$S \operatorname{sex} x E \operatorname{sex}$

1

664.23

1.69

NS

$S \operatorname{sex} x E / E \operatorname{sex}$

8

392.76

$\mathrm{PR} \times \mathrm{S}$ sex

1

3.80

$<1.00$

NS

$P R \times S \operatorname{sex} x E \operatorname{sex}$

1

40.00

$<1.00$. NS

$P R \times S \operatorname{sex} \times E / E$ sex

8

378.70

Tota1 
TABLE 15

Means and Standard Deviations

For Average Heart Rate

in Beats per Mìnute

$\begin{array}{lllrr}\text { Subclass } & \text { S Sex } & \text { E Sex } & \text { Mean } & \text { S.D. } \\ \text { Process } & \text { Male } & \text { Male } & 110.2 & 6.24 \\ \text { Process } & \text { Male } & \text { Female } & 97.0 & 17.70 \\ \text { Process } & \text { Female } & \text { Female } & 107.4 & 17.84 \\ \text { Process } & \text { Female } & \text { Male } & 100.4 & 13.27 \\ \text { Reactive } & \text { Male } & \text { Male } & 92.0 & 9.96 \\ \text { Reactive } & \text { Male } & \text { Female } & 80.0 & 9.10 \\ \text { Reactive } & \text { Female } & \text { Female } & 89.8 & 9.62 \\ \text { Reactive } & \text { Female } & \text { Male } & 90.4 & 17.66\end{array}$




\author{
TABLE 16 \\ Analysis of Variance \\ of Average Heart Rate \\ in Beats per Minute
}

\begin{tabular}{|c|c|c|c|c|}
\hline Source & $\mathrm{df}$ & MS & F & $\mathrm{p}$ \\
\hline E sex & 1 & 222.00 & 1.19 & NS \\
\hline $\mathrm{E} / \mathrm{E} \operatorname{sex}$ & 8 & 186.63 & & \\
\hline PR & 1 & 2466.00 & 31.87 & $<.001$ \\
\hline$P R \times E$ sex & 1 & 24.00 & $<1.00$ & NS \\
\hline $\mathrm{PR} \times \mathrm{E} / \mathrm{E}$ sex & 8 & 77.38 & & \\
\hline$S \operatorname{sex}$ & 1 & 49.00 & $<1.00$ & NS \\
\hline$S \operatorname{sex} x E \operatorname{sex}$ & 1 & 623.00 & 1.77 & NS \\
\hline$S \operatorname{sex} \times E / E \operatorname{sex}$ & 8 & 352.50 & & \\
\hline$P R \times S$ sex & 1 & 35.00 & $<1.00$ & NS \\
\hline$P R \times S \operatorname{sex} \times E \operatorname{sex}$ & 1 & 50.00 & $<1.00$ & NS \\
\hline$P R \times S \operatorname{se} x \times E / E \operatorname{sex}$ & 8 & 279.13 & & \\
\hline
\end{tabular}

Total 


\section{TABLE 17}

Means and Standard Deviations

for Heart Rate Variability

$\begin{array}{lllll}\text { Subclass } & \text { S Sex } & \text { E Sex } & \text { Mean } & \text { S.D. } \\ \text { Process } & \text { Male } & \text { Male } & 1.46 & 0.30 \\ \text { Process } & \text { Male } & \text { Female } & 2.18 & 0.78 \\ \text { Process } & \text { Female } & \text { Female } & 1.58 & 0.43 \\ \text { Process } & \text { Female } & \text { Male } & 1.78 & 0.66 \\ \text { Reactive } & \text { Male } & \text { Male } & 1.32 & 0.46 \\ \text { Reactive } & \text { Male } & \text { Female } & 2.30 & 1.41 \\ \text { Reactive } & \text { Female } & \text { Female } & 1.36 & 0.40 \\ \text { Reactive } & \text { Female } & \text { Male } & 1.86 & 0.29\end{array}$


TABLE 18

$$
\begin{aligned}
& \text { Analysis of Variance } \\
& \text { of Heart Rate Variability }
\end{aligned}
$$

Source

E sex

E/E sex

PR

PR $\times$ E sex

PR $\times$ E/E sex

$S \operatorname{sex}$

$S \operatorname{sex} x E \operatorname{sex}$

$S \operatorname{sex} x E / E \operatorname{sex}$

PR $x$ S sex

PR $\times S$ sex $x E \operatorname{sex}$

PR $x \mathrm{~S} \operatorname{sex} \times E / E \operatorname{sex}$

Tota1 df

1

8

1

1

8

1

1

8

1

1

8

MS

0.63

1.03

0.61

0.02

$<1.00$

$<1.00$

0.95

0.26

$<1.00$

4.24

0.27

0.00

0.00

$<1.00$

$<1.00$

0.48

$\mathrm{p}$

NS

$15.70<.01$

NS

NS 
TABLE 19

Means and Standard Deviations

for Initial $\mathrm{G} \mathrm{S} \mathrm{R}^{1}$

$\begin{array}{llllr}\text { Subclass } & \text { S Sex } & \text { E Sex } & \text { Mean } & \text { S.D. } \\ \text { Process } & \text { Male } & \text { Male } & 113.4 & 10.91 \\ \text { Process } & \text { Male } & \text { Female } & 102.8 & 17.37 \\ \text { Process } & \text { Female } & \text { Female } & 114.4 & 35.81 \\ \text { Process } & \text { Female } & \text { Male } & 103.2 & 21.24 \\ \text { Reactive } & \text { Male } & \text { Male } & 98.8 & 8.93 \\ \text { Reactive } & \text { Male } & \text { Female } & 112.2 & 14.64 \\ \text { Reactive } & \text { Female } & \text { Female } & 98.0 & 9.06 \\ \text { Reactive } & \text { Female } & \text { Male } & 106.8 & 25.07\end{array}$

1 Initial $\log$ of skin conductance $x 100$. 
TABLE 20

Analysis of Variance

of Initial GSR ${ }^{1}$

Source

df

MS

F

$\mathrm{p}$

E sex

1

14.00

$<1.00$

NS

E/E sex

8

348.13

PR

1

193.00

$<1.00$

NS

PR $x$ E sex

1

71.00

$<1.00$

NS

$P R \times E / E$ sex

8

498.25

$S$ sex

1

12.00

$<1.00$

NS

$S \operatorname{sex} x E \operatorname{sex}$

1

0.00

$<1.00$

NS

$S \operatorname{sex} \times E / E \operatorname{sex}$

8

497.62

PR $x$ S sex

1

39.00

$<1.00$

NS

$P R \times S \operatorname{sex} x E \operatorname{sex}$

1

2172.00

4.27

NS

$\mathrm{PR} \times \mathrm{S} \operatorname{sex} \times \mathrm{E} / \mathrm{E} \operatorname{sex}$

8

509.13

Total

39

1

Initial log of skin conductance x 100 . 
TABLE 21

Means and Standard Deviations for Average G S R ${ }^{1}$

Subclass

Process

Process

Process

Process

Reactive

Reactive

Reactive

Reactive
$\underline{S} \operatorname{Sex}$

Male

Male

Female

Female

Male

Male

Female

Female $\underline{\text { E Sex }}$

Male

Female

Female

Male

Male

Female

Female

Male
Mean

69.6

112.2

114.8

95.6

103.4

74.8

104.2

93.6
S.D.

20.12

51.54

39.03

52.37

24.39

23.38

26.42

47.68

1 Mean of minute readings of skin conductance x 100 . 
TABLE 22

$$
\begin{gathered}
\text { Analysis of Variance } \\
\text { of Average G S R }
\end{gathered}
$$

Source

E sex

E/E sex

PR

PR x E sex

$\mathrm{PR} \times \mathrm{E} / \mathrm{E} \operatorname{sex}$

$S \operatorname{sex}$

$S \operatorname{sex} x E \operatorname{sex}$

$S \operatorname{sex} x E / E \operatorname{sex}$

PR $x$ S sex

PR $x \mathrm{~S} \operatorname{sex} \times E$ sex

$P R \times S \operatorname{sex} \times E / E$ sex

Total df

1

8

1

1

8

1

1

8

1

1

8

1269.05

$<1.00$

2328.62

(1)

164.05

$<1.00$

NS

3880.00

1.44

NS

2688.93

1452.05

1.87

$<1.00$

NS

56.00

776.68

20.60

$<1.00$

NS

2579.25

1.92

1344.52

$p$

NS

NS

8

8

39

${ }^{1}$ Mean of minute readings of skin conductance $x 100$. 


\section{TABLE 23}

Means and Standard Deviations

for GSR Variability

$\begin{array}{lllcr}\text { Subclass } & \text { S Sex } & \text { E Sex } & \text { Mean } & \text { S.D. } \\ \text { Process } & \text { Male } & \text { Male } & 5.0 & 3.10 \\ \text { Process } & \text { Male } & \text { Female } & 16.4 & 17.51 \\ \text { Process } & \text { Female } & \text { Female } & 22.6 & 6.45 \\ \text { Process } & \text { Female } & \text { Male } & 21.2 & 31.01 \\ \text { Reactive } & \text { Male } & \text { Male } & 19.0 & 11.03 \\ \text { Reactive } & \text { Male } & \text { Female } & 8.8 & 6.91 \\ \text { Reactive } & \text { Female } & \text { Female } & 33.0 & 22.25 \\ \text { Reactive } & \text { Female } & \text { Male } & 21.4 & 22.21\end{array}$


TABLE 24

Analysis of Variance

of G S R Variability

Source

E sex

E/E sex

PR

PR $x$ E sex

PR $x$ E/E sex

$S$ sex

$S \operatorname{sex} x E \operatorname{sex}$

$S \operatorname{sex} x E / E \operatorname{sex}$

PR x S sex

PR $x S \operatorname{sex} \times E$ sex

$P R \times S \operatorname{sex} \times E / E \operatorname{sex}$

Total df

1

8

1

1

8

1

1

8

1

1

8

1513.00

82.00

678.88

14.00

795.00

175.75

208.75 $\mathrm{p}$

NS

$<1.00$

$<1.00$

NS

$<1.00$

NS

$2.23 \quad$ NS

$<1.00$ NS

$<1.00 \quad$ NS

$4.52 \quad$ NS 


\section{TABLE 25}

Means and Standard Deviations

for Initial Body Movement

(Rate per Minute)

Subclass

Process

Process

Process

Process

Reactive

Reactive

Reactive

Reactive
$\underline{S} \operatorname{Sex}$

Male

Male

Female

Female

Male

Male

Female

Female
E Sex

Male

Female

Female

Male

Male

Female

Female

Male
Mean

7.4

4.22

19.17

12.85

11.41

8.8

6.01

3.0

2.28

10.8

9.28

8.84 
TABLE 26

\author{
Analysis of Variance \\ of Initial Body Movement \\ (Rate per Minute)
}

\begin{tabular}{|c|c|c|c|c|}
\hline Source & $d f$ & MS & $\mathrm{F}$ & $\mathrm{p}$ \\
\hline$E \operatorname{sex}$ & 1 & 33.00 & $<1.00$ & NS \\
\hline $\mathrm{E} / \mathrm{E} \operatorname{sex}$ & 8 & 169.38 & & \\
\hline PR & 1 & 4.00 & $<1.00$ & NS \\
\hline PR $x E$ sex & 1 & 162.00 & $<1.00$ & NS \\
\hline $\mathrm{PR} \times \mathrm{E} / \mathrm{E} \operatorname{sex}$ & 8 & 236.38 & & \\
\hline$S \operatorname{sex}$ & 1 & 83.00 & $<1.00$ & NS \\
\hline$S \operatorname{sex} x E \operatorname{sex}$ & 1 & 9.00 & $<1.00$ & NS \\
\hline$S \operatorname{sex} x E / E \operatorname{sex}$ & 8 & 260.63 & & \\
\hline PR x S sex & 1 & 258.00 & $<1.00$ & NS \\
\hline$P R \times S \operatorname{sex} \times E \operatorname{sex}$ & 1 & 59.00 & $<1.00$ & NS \\
\hline $\mathrm{PR} \times \mathrm{S} \operatorname{sex} \times \mathrm{E} / \mathrm{E} \operatorname{sex}$ & 8 & 533.25 & & \\
\hline
\end{tabular}

Total 
TABLE 27

Means and Standard Deviations

for Average Body Movement

Subclass

$\underline{S} \operatorname{Sex}$

$\underline{E} \operatorname{Sex}$

Means

S.D.

Process

Male

Male

8.0

3.41

Process

Male

Female

13.8

14.66

Process

Female

Female

10.8

13.60

Process

Female

Male

6.6

6.34

Reactive

Male

Male

12.6

16.76

Reactive

Male

Female

5.4

3.01

Reactive

Female

Female

11.6

14.87

Reactive

Female

Male

16.4

24.60 
TABLE 28

Analysis of Variance

of Average Body Movement

\begin{tabular}{lrrrr} 
Source & df & \multicolumn{1}{c}{ MS } & F & p \\
E sex & 1 & 3.60 & $<1.00$ & NS \\
E/E sex & 8 & 190.78 & & \\
PR & 1 & 25.60 & $<1.00$ & NS \\
PR X E sex & 1 & 342.80 & 2.44 & NS \\
PR X E/E sex & 8 & 140.42 & & \\
S sex & 1 & 22.50 & $<1.00$ & NS \\
S sex X E sex & 1 & 27.00 & $<1.00$ & NS \\
S sex X E/E sex & 8 & 284.53 & & \\
PR X S sex & 1 & 136.90 & $<1.00$ & NS \\
PR X S sex E sex & 1 & 515.20 & 2.43 & NS \\
PR X S sex E E E sex & 8 & 212.31 & &
\end{tabular}

Total 
TABLE 29

\begin{abstract}
Means and Standard Deviations
for Body Movement Variability
\end{abstract}

Subclass

S Sex

E Sex

Mean

S.D.

Process

Male

Male

4.62

1.23

Process

Male

Female

1.90

0.97

Process

Female

Female

3.64

2.06

Process

Female

Male

3.10

1.54

Reactive

Male

Male

5.38

3.89

Reactive

Male

Female

5.24

1.14

Reactive

Female

Female

4.60

2.66

Reactive

Female

Male

2.94

2.22 
TABLE 30

Analysis of Variance

of Body Movement Variability

$\begin{array}{lcccc}\text { Source } & \text { df } & \text { MS } & \text { F } & p \\ \text { E sex } & 1 & 0.30 & <1.00 & \text { NS } \\ \text { E/E sex } & 8 & 3.90 & & \\ \text { PR } & 1 & 14.30 & 2.77 & \text { NS } \\ \text { PR X E sex } & 1 & 8.70 & 1.69 & \text { NS } \\ \text { PR X E/E sex } & 8 & 5.16 & & \\ \text { S sex } & 1 & 4.90 & <1.00 & \text { NS } \\ \text { S sex X E sex } & 1 & 16.30 & 3.31 & \text { NS } \\ \text { S sex } x \text { E/E sex } & 8 & 4.93 & & \\ \text { PR } x \text { S sex } & 1 & 7.10 & <1.00 & \text { NS } \\ \text { PR X S sex E sex } & 1 & 1.50 & <1.00 & \text { NS } \\ \text { PR X S sex X E/E sex } & 8 & 9.34 & & \end{array}$


show that physiological measures tend to be positively related to other variations of the same measure (e.g., average GSR to GSR variability and initial GSR). The relationship between behavioral and physiological measures was significant in several instances. The degree of illness (Moran relatedness) was negatively correlated with the rate of body movement across the testing session and with breathing variability. Both of the latter measures involve skeletal muscles and can be consciously controlled. Degree of illness was also negative1y correlated with average reaction time. Thus, patients who gave "healthier" word associations moved around less during the whole session, showed less reaction in breathing changes, and were less inclined to block in responding. The per cent of associations not recalled was positively correlated with average GSR conductance and with initial and average heart rate. The demographic data were not significantly correlated with the behavioral or physiological data (see Table 31). 
Correlation of Physiological, Behavioral, and Demographic Data

1 Average GSR

2 Average Body Movement

3 Average Respiration

4 Average Heart Rate

5 GSR Variability

6 Body Movement Variability

7 Respiration Variability

8 Heart Rate Variability

9 Initial GSR

10 Initial Body Movement

11. Initial Respiration

12 Initial Heart Rate

13 Relatedness of Associations

14 Reaction Time

$15 \%$ Not Recalled

$16 \%$ Life in Hospital
1

.22

$-.05 \quad .23 \quad-$

$.04 \quad .04 \quad .15$

$.42^{+}-.06-.13 \quad-.15 \quad:-$

$\begin{array}{llllll}-.22 & .16 & .09 & -.27 \quad .03 & -.27\end{array}$

$\begin{array}{lllll}.14 & .46^{+} .37^{*} & -.02 & -.23 & .18\end{array}$

$\begin{array}{lllllllll}-.03 & .09 & .05 & -.30 & -.21 & .04 & .04 & -\end{array}$

$-.50^{++}-.25--.23 \quad .04 \quad-.33^{*} .11 \quad-.24 \quad .05 \quad-$

$\begin{array}{lllllllll}.23 & .89^{++} .20 & .05 & .02 & -.08 & .35^{*} & -.01 & -.28 & -\end{array}$

$\begin{array}{lllllllllll}-.04 & .20 & .92^{++} & .05 & -.10 & .19 & .47^{+} & .02 & -.20 & .13 & -\end{array}$

$\begin{array}{llllllllll}.05 & .08 & .11 & .98^{++}-.12 & -.25 & -.02 & -.26 & .02 & .09 & .01\end{array}$

$\begin{array}{llllllllllllllll}-.01 & -.32^{*} & .03 & -.15 & .04 & -.08 & -.37^{*} & .22 & .05 & -.25 & -.08 & -.14 & -\end{array}$

$\begin{array}{llllllllllllllllll}-.06 & .05 & -.19 & .02 & -.15 & .03 & .24 & -.13 & .08 & -.01 & -.17 & .05 & -.37^{*} & -\end{array}$

$\begin{array}{lllllllllllllllll}.35 * & .07 & -.10 & .40^{+} & .03 & -.26 & .12 & -.19 & .01 & .13 & -.01 & .39 & -.24 & .18 & -\end{array}$

$\begin{array}{lllllllllllllllll}.09 & .10 & -.18 & .11 & .17 & .07 & .13 & .26 & -.08 & .05 & -.08 & .18 & -.06 & -.03 & .03\end{array}$

${ }^{*} \mathrm{r}=.31 ; \underline{\mathrm{p}}<.05$ 


\section{Discussion}

The findings of the present study did not support the first hypothesis (that word associations would show less disturbance when the $\underline{E}$ and $\underline{S}$ were of the same sex). On the contrary, three of the four groups performed more poorly in a same-sex E-S situation. These results support those of Littig and Waddell (1967), who found poorer performance with same-sex Es and Ss, but differ from those of Lefcourt

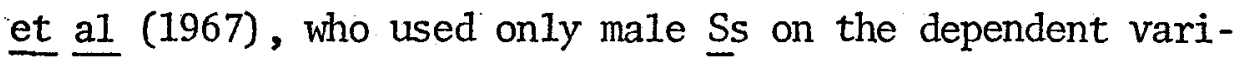
able measure. The process males in the present study did not react significantly to the sex of the $E$ while those of Lefcourt et al (1967) did.

Results using the heart rate variability measure supported the general hypothesis of less stress reaction in same-sex E-S situations. The finding of increased heart rate variability with heterosexual E-S conditions indicates greater stress reactivity in this situation. Thus, while the converse of the first hypothesis was found when analyzing the word associations, the Ss showed less stress response at the physiological level with Es of the same sex.

The second hypothesis, that $\underline{E}$ sex differences would have more effect on reactive than on process schizophrenics, was supported by the results of the initial breathing rate measure. Both male and female reactives showed significantly higher initial respiration rates with male Es than with female Es, while the process groups showed no systematic 
effect of $\underline{E}$ sex. One possible interpretation of these data is that, as Broen (1968) has suggested, physiological variations are caused by multiple factors, one of which is an anticipatory set, distinct from reaction to stress. Since reactive patients are more likely to react to stress, it is reasonable to speculate that they might also be more likely to set themselves physiologically in order to be better prepared for conditions they expect to experience. Why this set..should be more apparent in the presence of a male examiner is not clear, but might be related to personality variables which are generally associated with the male sex (e.g., aggressiveness) or to the expectation that E would be male which is usually the case in psychological examinations.

The significant main effect on the process-reactive dimension using the heart rate measure offered evidence in support of a theory of arousal levels in schizophrenia that would take into account three separate aspects of arousal, namely, basal level, arousal under stress (reactivity), and difference measures between basal level and reactivity. The correction for basal-level differences in evaluating arousal levels seems of the utmost importance. Angyal, Freeman, and Hoskins (1940) reported that in a number of studies measuring physiological reactivity to fairly stressful stimulus conditions, schizophrenics in general tended to be hyporeactive. Gunderson (1953) found schizophrenics' 
basal physiological levels to be significantly higher than those of normals. Reynolds (1963), proceeding on the assumption that schizophrenics have high basal physiological levels but are hyporeactive to additional stimulation, combined the two experimental situations into one investigation, using successive periods of rest and stress. He found process patients to be abnormally high on arousal measures, both during periods of relaxation and following stressors. However, when the score in the prior rest period was subtracted from the level under stress for each of the measures and stress periods, there were few significant differences between groups. When these did occur, it was the normals who showed the greatest change in response to stimulation. The interpretation that schizophrenics show lower responsivity seems warranted when the effects of homeostatic mechanisms are considered in the context of a high base system. Moreover, the baroreceptors of the cardio-aortic area, with their location close to the heart, are sensitive detectors of increased heart rate. Lacey and Lacey (1966) and Lacey (1967) have reviewed considerable evidence that shows rather convincingly that these baroreceptors are normally active, with attenuating effects on both the cortex and heart rate, and that further stimulation of the baroreceptors can produce a decrease in cortical electrical activity, a reduction in the effects of stimulation, an inhibition of motor activity, and decelerated cardiovascular functioning. The level of stress, then, should be an important 
factor in the reactivity of process schizophrenics. In the present study, which incorporated stressful conditions, the process groups' reactions were in keeping with the findings of Reynolds (1963) and the activation theory of Lacey (1967). 
Summary

This investigation studied the word associations of schizophrenic patients and concurrently assessed physiological indices of emotional arousal (or stress reactions) under stressful conditions. The hypothesis that word associations would show less disturbance when the $\underline{E}$ and $\underline{S}$ were of the same sex was not supported. In fact, for the recall of associations measure, three of the four groups performed more poorly when $E$ and $\underline{S}$ were the same sex. However, results using the heart rate variability measure supported the general hypothesis of less stress reaction when the $\underline{E}$ and $\underline{S}$ were the same sex. Heart rate variability was significantly greater with heterosexual $\underline{E}$ - $\underline{S}$ pairings than with same-sex $\underline{E}-\underline{S}$ pairs.

The second hypothesis, that examiner sex differences would have more effect on reactive than on process schizophrenics was partially supported by the findings in the initial breathing rate. For this measure, both male and female reactives showed higher initial respiration rates with male Es than with female Es, while the process groups showed no systematic effect of $\underline{E}$ sex.

Generally, effects of $\underline{E}$ sex and the process-reactive classification were found in both behavioral and physiological measures, but the institutionalization measure was not related to any other measure. The presence of a female $\underline{E}$ was 
accompanied by lower initial respiration rates in male and female reactive groups. Also, when $\underline{E}$ and $\underline{S}$ were of different sexes, heart rate variability was greater. Finally, in all groups except the process males, the associational processes were more stable (better recall of associations) with heterosexual $\underline{E}$ and $\underline{S}$ pairs.

Process-reactive differences were found in heart rate and stability of associations. The combined male and female process Ss showed a higher initial and average heart rate. The combined reactives showed more stable associational processes. When the behavioral, physiological, and demographic measures were intercorrelated for the entire group, relationships between behavioral and physiological measures were found which appeared to be independent of institutionalization and the process-reactive distinction. In general, lower levels of pathology, (i.e., healthier associations and greater stability of associations) were accompanied by less reaction to the stressful situation, (i.e., lower body movement rates, skin conductance, and heart rates), as well as by less variability in breathing throughout the examination and less tendency to block (i.e., shorter reaction times). 


\section{References}

Angyal, A., Freeman, H., and Hoskins, R. G. Physiologic aspects of schizophrenic withdrawal. 'Archives of Neurology and Psychiatry, 1940, 44, 621-626.

Berman, G. Conceptual functioning of schizophrenics classified along the process-reactive continuum. Dissertation Abstracts, 1963, 24, 389.

Bernstein, A. R. Electrodermal base level, tonic arousal and adaptation in chronic schizophrenics. Journal of Abnormal Psychology, 1967, 72, 221-232.

Brenner, A. R. Effects of prior experimenter-subject relationships to the Kent-Rosanoff Word Association List in schizophrenics. Journal of Abnormal Psychology, $1967,72,273-276$.

Broen, W. E. Schizophrenia: Research and theory. New York: Academic Press, 1968.

Crider, A. B., Grinspoon, L., and Maher, B.A. Autonomic and psychomotor correlates of premorbid adjustment in schizophrenia. Psychosomatic Medicine, 1965, 27, 201-206.

Datta, L. E., and Drake, A.K. Examiner sex and sexual differentiation in preschool children's figure drawings. 
Journal of Projective Techniques and Personality

Assessment, 1968, 32(4), 397-399.

DeVault, S. H. Physiological responsiveness in reactive and process schizophrenia. 'Dissertation Abstracts, 1957, $17,1387$.

De Wolfe, A. S. The effect of affective tone on the verbal behavior of process and reactive schizophrenics. Journal of Abnormal and Social Psychology, 1962, $64,450-455$.

De Wolfe, A. S. Self-reports and case histories of schizophrenic patients: Reliability and validity of Phillips scale ratings. Journal of Clinical Psychology, $1968,24,415-418$.

Dokecki, P. R., Polidoro, L.G., and Cromwe11, R. L. Commonality and stability of word association responses in good and poor premorbid schizophrenics. Journal of Abnormal Psychology, 1965, 70, 312-316.

Fox, R. P. The experimenter variable in dream research. Psychophysiology, 1968, 4(3), 373.

Fuller, G. D. and Kates, S. L. Word association repertoires of schizophrenics and normals. Journal of Consulting and Clinical Psychology, 1969, 33, 497-500.

Glixman, A. F. Effects of examiner, examiner-sex, and subjectsex upon categorizing behavior. Perceptual and Motor Ski11s, 1967, 24(1), 107-117. 
Gunderson, E. K. Autonomic balance in schizophrenia. Unpublished doctoral dissertation, University of California, Los Angeles, 1953.

Humphries, C. C. Temporal variability and premorbid adjustment in schizophrenia. Dissertation Abstracts, 1961, 21, 2003.

Kintz, B. L., Delprato, D. J., Mettee, D. R., Persons, C. E., and Schappe, R. H. The experiment effect. 'Psychological Bulletin, 1965, 63(4), 223-232.

Lacey, J. I. Somatic response patterning and stress: Some revisions of activation theory. In M. H. Appley and R. Trumbul1 (Eds.), Psychological stress: Issues in research. New York: Appleton-Century-Crofts, 1967. Pp. 14-37.

Lacey, J. I., and Lacey, B. C. The relationship of resting autonomic activity to motor impulsivity. In The brain and human behavior. New York: Hafner Publishing Co., 1966. Pp. 144-209.

Lefcourt, H., Rotenberg, F., Buckspan, B., and Steffy, R. Visual interaction and performance of process and reactive schizophrenics as a function of examiner's sex. Journal of Personality, 1967, 35(4), 535-546.

Littig, L. W., and Wadde11, C. M. Sex and experimenter interaction in serial learning. Journal of Verbal Learming and Verbal Behavior, 1967, 6(4), 676-678. 
Lord, E. Experimentally induced variations in Rorschach performance. Psychological Monographs, 1950, 64, (Whole No. 316).

Moran, L. J. Vocabulary knowledge and usage among normal and schizophrenic subjects.' Psychological Monographs, 1953, 67, (Whole No. 370).

Moran, L. J., Mefford, R. B., and Kimble, J. P. Idiodynamic sets in word association. Psychological Monographs, 1964, 78, (Whole No. 579).

Moriarity, D., and Kates, S. L. Concept attainment of schizophrenics on materials involving social approval and disapproval. 'Journal of Abnormal and Social Psychology, 1962, 65, 355-364.

Phillips, L. Case history data and prognosis in schizophrenia. 'Journal of Nervous and Mental Disease, $1953,117,515-525$.

Reisman, J. M. Motivational differences between process and reactive schizophrenics. 'Journal of Personality, $1960,28,12-25$.

Reynolds, D. J. An investigation of the somatic response system in chronic schizophrenia. Dissertation Abstracts, 1963, 23, 4746.

Reynolds, R. D. Operant response as a function of the premorbid adjustment of schizophrenic subjects. Dissertation Abstracts, 1965, 26, 1173-1174. 
Ries, H. A. and Johnson, M. H. Conmonality of word associations and good and poor premorbid schizophrenia. Journal of Abnormal Psychology, 1967, $72,487-488$.

Rosentha1, R. Experimenter attributes as determinants of subjects' responses. 'Journal of Projective 'Techniques and Personality Assessment, 1963, 27(3), .324-331.

Rosenthal, R. The effect of the experimenter on the results of psychological research. In B. A. Maher (Ed.), Progress in experimental personality research.

New York: Academic Press, 1964. Pp 79-114. Rosentha1, R. Experimenter outcome-orientation and the results of the psychological experiment.'PsychoIogical Bulletin, 1964, 61, 405-412.

Rosentha1, R. Experimenter effects in behavior research.

New York: Appleton-Century-Crofts, 1966.

Schafer, R. Psychoanalytic interpretation in Rorschach testing. New York: Grune and Stratton, 1954. Smith, W. 0. Rotary pursuit performance in reactive and process schizophrenics. Dissertation Abstracts, $1961,21,2787-2788$.

Stevenson, H. W., and Allen, S. Adult performance as a function of sex of experimenter and sex of subject. Journal of Abnormal and Social Psychology, 1964, 68, 214-216. 
Stevenson, H. W., and Knights, R. M. Social reinforcement with normal and retarded children as a function of pretraining, sex of $\underline{\mathrm{E}}$, and sex of $\underline{\mathrm{S}}$. American Journa1 of Mental Deficiency, $1962,66,866-871$.

Struve, F. A. Classical cardiac conditioning with process and reactive schizophrenics and normals. Dissertation Abstracts, 1966, 26, 4082 .

True, J. E. Leaming of abstract responses by process and reactive schizophrenic patients. Psychological Reports, $1966,18,51-55$.

Walker, R. E., Davis, W. E., and Firetto, A. An experimenter variable: The psychologist-clergyman. Psychological Reports, 1968, 22, 709-714.

Walker, R. E., and Firetto, A. The clergyman as a variable in psychological testing. Journal for the Scientific Study of Religion, 1965, 4, 234-236.

Ward, W. D., and Carlson, W. A. Autonomic responsivity to variable input rates among schizophrenics classified on the process-reactive dimension. Journal of Abnomal Psychology, 1966, 71, 10-16.

Winkel, G. H., and Sarason, I. G. Subject, experimenter, and situational variables in research on anxiety. Journal of Abnormal and Social Psychology, 1964, $68(6), 601-608$. 
Zlotowșki, M., and Bakan, P. Behavioral variability of process and reactive schizophrenics in a binary guessing task. Journal of Abnormal and Social Psychology, $1963,66,185-187$. 


\section{APRROVAL SHEET}

The Dissertation submitted by RIta Kluczny McDonald has been read and approved by members of the Department of Psychology.

The final coptes have been examined by the director of the Dissertation and the signature which appears below verifles the fact that any necessary changes have been incorporated and that the Dissertation is now given final approval with reference to content and form.

The Dissertation is, therefore, accepted in partlal fulfiliment of the requirements for the degree of Doctor of Phllosophy.

$$
1-18-71
$$

Date

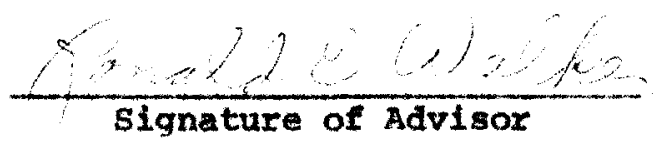

